J. Amer. Soc. Hort. Sci. 115(2):231-234. 1990.

\title{
Seed Germination of Fraser Fir: Timing of Irradiation and Involvement of Phytochrome
}

\author{
Paul H. Henry and Frank A. B1azich ${ }^{2}$ \\ Department of Horticultural Science, North Carolina State University, Raleigh, NC 27695-7609
}

Additional index words. Abies fraseri, light, seed testing, sexual propagation

\begin{abstract}
Two experiments investigated the relationship of light and temperature in seed germination of Fraser fir [Abies fraseri (Pursh) Poir.]. Irradiation during the warm portion of 9/15 hr thermoperiod of 20/10C and 30/20C increased germination percentages after 42 days, and the degree of stimulation depended on the timing of the light exposures. A 1-hr exposure was most effective during the latter part of the warm portion of the thermoperiods, and varying the time of irradiation had the greatest effect at $20 / 10 \mathrm{C}$. The involvement of phytochrome in this photomorphogenic response was ascertained by demonstration of red/far-red reversibility.
\end{abstract}

Seed germination of Fraser fir is enhanced by light (Adkins et al., 1984; Blazich and Hinesley, 1980). Although there is no absolute requirement for light, it stimulates both the amount and rate of germination (Adkins et al., 1984). The degree of stimulation is influenced by several environmental factors, of which duration of stratification (moist-prechilling) and germination temperature are most important. The optimal thermoperiod for nonstratified seeds is generally considered to be an 8/16-hr cycle of 30/20C (Heit, 1968; International Seed Testing Association, 1976). Adkins et al. (1984), however, reported slightly increased germination using an 8/16-hr thermoperiod of 15/25C. Light stimulates germination at all temperature regimes, but stimulation is greatest at lower temperatures (Adkins et al., 1984).

The minimum daily light requirement to achieve maximum seed germination of Fraser fir is unknown. Adkins et al. (1984) reported that a 1-hr exposure to cool-white fluorescent lamps [photosynthetic photon flux (PPF) (400 to $700 \mathrm{~nm}$ ) of 21 to 27 $\mu \mathrm{mol} \cdot \mathrm{s}^{-1} \cdot \mathrm{m}^{-2}$ ]was sufficient to maximize germination of nonstratified seeds at a 9/15-hr thermoperiod of 30/20C. Research reported herein initially used these findings as a guideline. However, we realized that the timing of the l-hr light exposure appeared to affect germination during an alternating temperature cycle. This research, therefore, investigated the effect of exposing seeds to $1 \mathrm{hr}$ of light at various times during the warm portions of two thermoperiod. An additional study was conducted to determine if the germination response of Fraser fir is phytochrome-mediated.

\section{Materials and Methods}

General procedures. Seeds were collected in 1981 by the North Carolina Forest Service from Roan mountain [lat. $36^{\circ} 01^{\prime} \mathrm{N}$, long. $82^{\circ} 05^{\prime} \mathrm{W}$, elevation $\left.=1900 \mathrm{~m}\right]$, dried to a moisture content of $4 \%$ to $6 \%$ and stored in a polyethylene bag at $-17 \mathrm{C}$. Abnormal, damaged, undersized, and resinous seeds were removed by hand before initiation of the experiments.

Received for publication 1 Dec. 1988. Paper no. 11490 of the Journal Series of the N.C. Agricultural Research Service (NCARS), Raleigh, NC 27695-7643. From a thesis submitted by P.H.H. in partial fulfillment of the requirements for the MS degree. Use of trade names in this publication does not imply endorsement by the NCARS of products named nor criticism of similar ones not mentioned. Assistance of J.R. Acedo, the staff of the Southeastern Plant Environment Laboratory (Phytotron), and the North Carolina Forest Service is gratefully acknowledged. The cost of publishing this paper was defrayed in part by the payment of page charges. Under postal regulations, this paper therefore must be hereby marked advertisement solely to indicate this fact.

'Graduate Research Assistant.

${ }^{2}$ Professor.
Nonstratified seeds were sown in 9-cm, covered glass petri dishes containing moist blotters (Anchor Seed Germination Paper, St. Paul, Minn. ). Dishes were placed in opaque, black cloth bags and light treatments were imposed by removal of dishes from the bags at appropriate times. The criterion for germination was radicle emergence $\geq 2 \mathrm{~mm}$. For fungal control, seeds were sprayed on days $1,4,7$, and weekly thereafter with a $300 \mathrm{mg}$ aqueous suspension of methyl[1-[(butylamino)carbonyl]-1Hbenzimidazol-2-yl]carbamate (benomyl)/liter (Adkins, 1983). About $0.2 \mathrm{ml}$ of liquid was applied per dish on each occasion. Germination blotters were kept moist with tap water throughout the experiments, and seeds exhibiting any signs of decay were immediately removed from the dishes.

Percent germination was calculated as a mean based on the number of replications per treatment. Means were compared by the LSD test (5\% level).

Timing of irradiation-Expt. 1. Seeds were removed from storage and sown in Mar. 1987. Dishes were randomized on metal trays and placed inside growth chambers [C-chambers (Downs and Thomas, 1983)] maintained at 9/15-hr thermoperiod of $20 / 10 \mathrm{C}$ and $30 / 20 \mathrm{C}$. Temperatures varied within $\pm 0.5 \mathrm{C}$ of the set point and relative humidity was $\approx 70 \%$ (Downs and Thomas, 1983). The warm portion of the thermoperiod started at 8:00 $\mathrm{AM}$ and ended at 5:00 PM.

Within each chamber, seeds were exposed to light for one of the following intervals: 11:00 AM-12:00 PM, 12:00-1:00 PM, 1:00-2:00 PM, 2:00-3:00 PM, 3:00-4:00 PM, 4:00-5:00 PM, 8:00 AM-5:00 PM, or constant darkness. Chambers were equipped with cool-white fluorescent lamps that provided a PPF level $(400-700 \mathrm{~nm})$ of 40 to $46 \mu \mathrm{mol} \cdot \mathrm{s}^{-1} \cdot \mathrm{m}^{-2}$ as measured with a cosine-corrected LI-COR LI-185 quantum/radiometer/photometer (LI-COR, Lincoln, Neb.).

The experimental unit, consisting of 50 seeds, was replicated six times and germination was recorded every 3 days for 42 days. For seeds exposed to light, benomyl applications and germination counts were carried out during the period of exposure. For seeds germinated in darkness, these procedures were conducted under a fluorescent lamp equipped with a green acetate filter (Rosco Laboratories, Port Chester, N.Y.).

Internal seed temperature was monitored throughout several 24-hr cycles with a 33-gauge thermocouple. At all times, seed temperature mirrored growth chamber temperature with no significant lag period. In addition, seed temperature did not rise in excess of 1C while the seeds were irradiated.

Involvement of phytochrome-Expt. 2. Seeds were removed from storage and sown in July 1987. Dishes were randomized on metal trays and placed in a Pfeiffer seed germinator maintained at a 9/15-hr thermoperiod of 20/10C. Temperatures var- 
ied within $\pm 1 \mathrm{C}$ of the set point and relative humidity was $\approx 100 \%$ (Downs and Thomas, 1983). The chamber was adjusted so that the warm portion of the cycle started at 8:00 AM and ended at 5:00 PM. Treatments were divided into two groups, based on the time during the warm, 9-hr portion of the thermoperiod that the seeds were exposed to light. One-half of the irradiation treatments began at 8:30 AM and the other half began at 4:00 PM. Starting at 8:30 AM assured that treatments occurred only after seed temperature had risen to 20C. Both groups of seed were exposed to red light for durations of either $1,2,4,8,16$, or 32 min. An additional treatment, in both groups, subjected seeds to $32 \mathrm{~min}$ of red light, followed immediately by $32 \mathrm{~min}$ of far-red light.

Light treatments were imposed by setting petri dishes under red and far-red light sources adjacent to the germinators. Red light was supplied by six, red-filtered (Plexiglass 2444), 40-W cool-white fluorescent lamps resulting in photon flux levels from $600-700 \mathrm{~nm}$ and $300-1100 \mathrm{~nm}$ of $14.9 \mu \mathrm{mol} \cdot \mathrm{s}^{-1} \cdot \mathrm{m}^{-2}$ and 19.1 $\mu \mathrm{mol} \cdot \mathrm{s}^{-1} \cdot \mathrm{m}^{-2}$, respectively (measured with a LI-COR LI-1800 spectroradiometer, 2-nm bandwidth) (Fig. 1A). Light from four $150-\mathrm{W}$ incandescent lamps was transmitted through water and a FRF-700 filter (Carolina Biological, Burlington, N.C. ), resulting in far-red light and photon flux levels from 700-800 nm and $300-1100 \mathrm{~nm}$ of $164.5 \mu \mathrm{mol} \cdot \mathrm{s}^{-1} \cdot \mathrm{m}^{-2}$ and 892.0 $\mu \mathrm{mol} \cdot \mathrm{s}^{-1} \cdot \mathrm{m}^{-2}$, respectively (measured with a LI-COR LI-1800 spectroradiometer, 2-nm bandwidth) (Fig. 1B). Heat accumulation from both the red and far-red light sources was prevented by adequate ventilation.

The experimental unit, consisting of 100 seeds, was replicated four times and total germination was recorded after 28

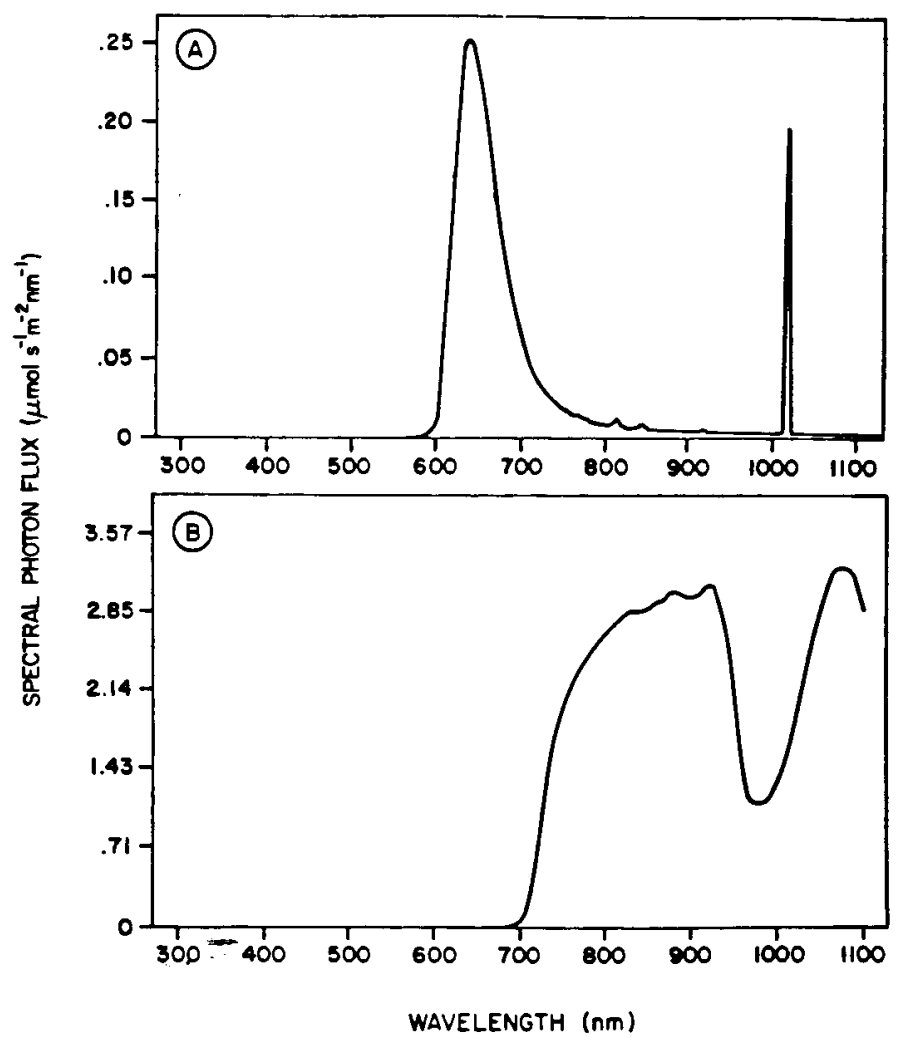

Fig. 1. Spectral distribution of red and far-red light source. (A) Red light source; photon flux $(300-1100 \mathrm{~nm})=19.1 \mu \mathrm{mol} \cdot \mathrm{s}^{-1} \cdot \mathrm{m}^{-2}$. (B) Far-red light source; photon flux $(300-1100 \mathrm{~nm})=892.0$ $\mu \mathrm{mol} \cdot \mathrm{s}^{-1} \cdot \mathrm{m}^{-2}$. days. Germination counts were not conducted during the course of the experiment to prevent exposure of the seeds to any alternative light source. Benomyl applications were conducted while seeds were irradiated or, for seeds germinated in darkness, while under a fluorescent lamp equipped with a green acetate filter.

\section{Results}

Timing of irradiation-Expt. 1. Exposure to light increased 42-day germination of Fraser fir and the degree of stimulation depended on when the seeds were irradiated (Fig. 2). At both thermoperiods, 1-hr exposures between 2:00 and 5:00 PM were more effective in promoting germination than similar exposures between 11:00 $\mathrm{AM}$ and 1:00 PM. An earlier study tested the effect of 1-hr irradiations between 8:00 and 11:00 AM. Seeds receiving these treatments germinated at percentages within $\pm 5 \%$ of the totals observed for the 11:00 AM-12:00 PM exposures (data not presented).

The germination response to the 9-hr (8:00 AM-5:00 PM) irradiation differed at the two thermoperiod (Fig. 2). At 30/ 20C, germination was equivalent to that obtained with the 1-hr exposures from 2:00-5:00 PM. At 20/10C, however, this treatment reduced germination to a level similar to that of the 1-hr exposures from 11:00 AM-1:00 PM.

Providing the light treatments at different times had the greatest effect at 20/10C (Fig. 2). At 20/10C, maximum germination (42\%) for irradiated seeds was 3.5 times greater than minimum germination $(12 \%)$, In contrast, maximum germination $(58 \%)$ of irradiated seeds at 30/20C was just 1.45 times greater than minimum germination (40\%). Although total germination was influenced by timing of light treatments, germination within a thermoperiod began on the same day, regardless of irradiation schedule (Fig. 3).

Involvement of phytochrome-Expt. 2.. Exposure of seeds to red light confirmed results of Expt. 1 and documented involvement of phytochrome in seed germination of Fraser fir. Seeds irradiated at 4:00 PM, near the end of the warm portion of the thermoperiod, germinated at a much higher percentage than seeds irradiated at 8:30 AM (Fig. 4). For both groups of seeds, a 2min exposure to red light was sufficient to maximize germination (LSD, 5\%). Far-red light reversed stimulation provided by

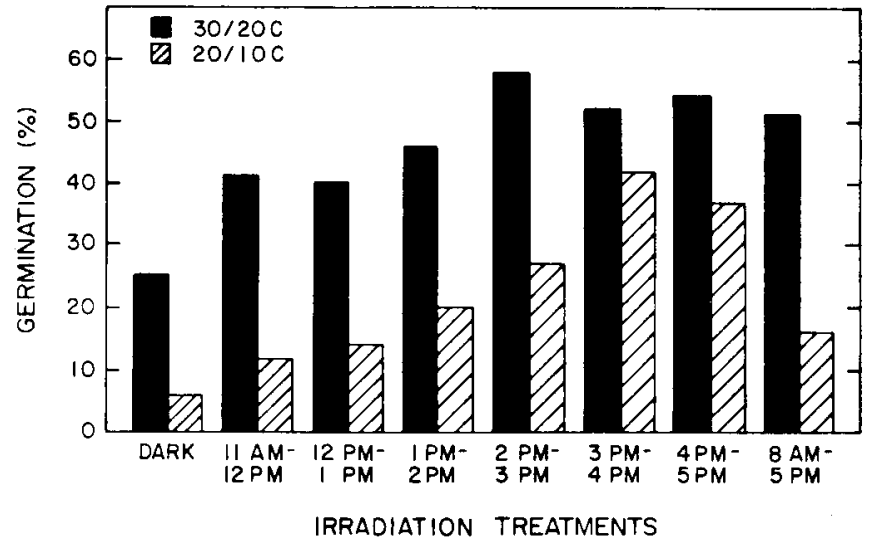

Fig. 2. Percent germination after 42 days for seeds of Fraser fir irradiated during the high-temperature portion of a 9/15-hr thermoperiod of $20 / 10 \mathrm{C}$ or $30 / 20 \mathrm{C}$. $\mathrm{LSD}_{0.05}=3.7$ for comparing means within irradiation treatments or temperature regimes. 


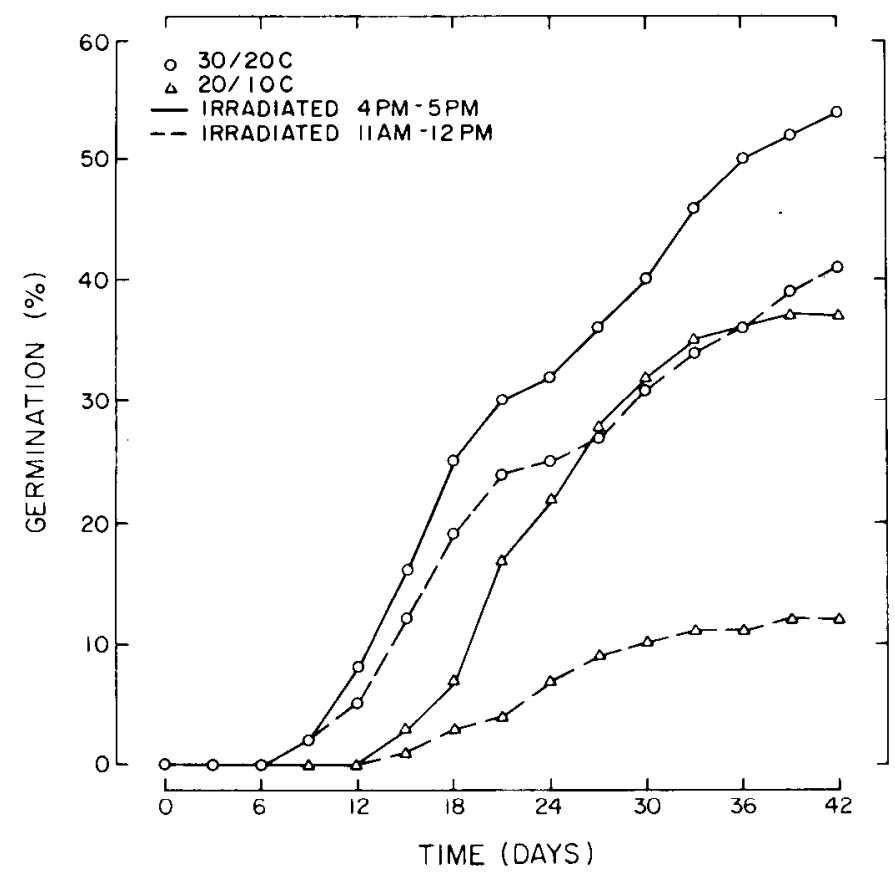

Fig. 3. Time course of Fraser fir germination for seeds irradiated at various times during the high-temperature portion of a $9 / 15-\mathrm{hr}$ thermoperiod of $20 / 10 \mathrm{C}$ or $30 / 20 \mathrm{C}$.

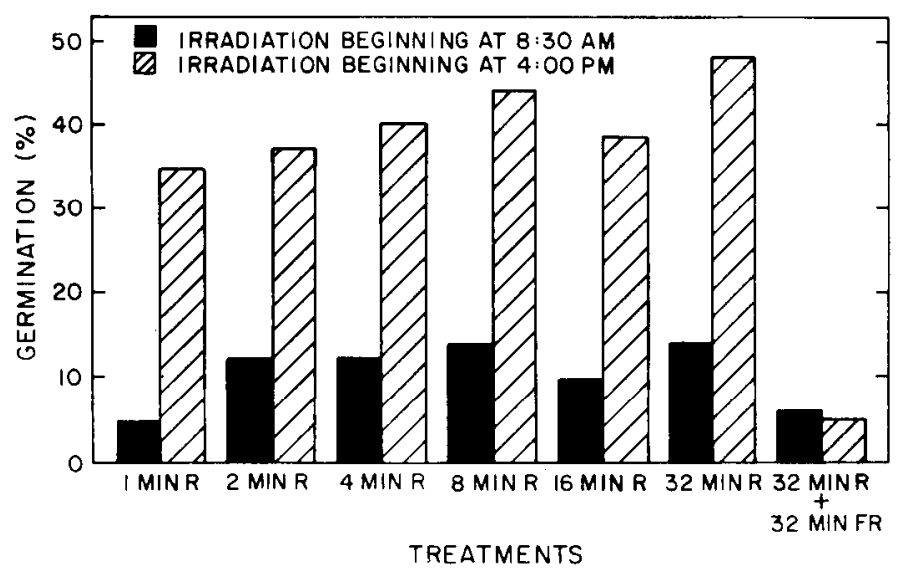

Fig. 4. Percent germination after 28 days for seeds of Fraser fir irradiated during the high-temperature portion of a 9/15-hr, 20/10C thermoperiod. $\mathrm{R}=$ irradiated with red light; $\mathrm{FR}=$ irradiated with far-red light (immediately following red irradiation). $\mathrm{LSD}_{0.05}=9.9$ for comparing means within irradiation treatments or irradiation times.

red light and reduced germination to 690, which was equivalent to that of seeds germinated in darkness.

\section{Discussion}

Phytochrome exists in two interconvertible forms, one of which stimulates germination and has maximum absorption in the farred region at $730 \mathrm{~nm}\left(\mathrm{P}_{\mathrm{fr}}\right)$, and the other which has maximum absorption at $666 \mathrm{~nm}\left(\mathrm{P}_{\mathrm{r}}\right)$ (Datta and Roux, 1985; Vierstra and Quail, 1983). Absorption of red light by $\mathrm{P}_{\mathrm{r}}$ or far-red light by $\mathrm{P}_{\mathrm{fr}}$ results in conversion to the other form. This conversion is usually incomplete; the two forms exist in a ratio that varies depending on the light source. Fluorescent lamps, as used in Expt. 1, shift the ratio towards $\mathrm{P}_{\mathrm{fr}}$ and promote germination.
Reversibility of a red promoted response by far-red radiation, as in Expt. 2, demonstrates that phytochrome is the photoreceptor involved in the response (Fig. 4).

Phytochrome reactions consist of two distinct processes. The initial step is absorption of photons by the phytochrome molecule, followed by the involvement of this molecule in subsequent metabolic reactions. The initial step is not temperaturedependent (Smith, 1975); light will be absorbed by phytochrome regardless of the temperature. The second step, however, is temperature-dependent, since temperature affects most aspects of cellular metabolism (Smith, 1975).

There are many possible mechanisms by which "activated" phytochrome might stimulate germination. In most proposed models, the initial molecular event is the interaction between $\mathrm{P}_{\mathrm{fr}}$ and a "receptor", the nature of which is unknown (Song, 1983). It is this interaction between $P_{f r}$ and its receptor that is influenced by temperature. The capacity to synthesize and/or translocate the receptor may be impaired when seeds are at a cooler-than-optimal temperature. Or, in a similar manner, one of the metabolic intermediaries required for germination might be suppressed due to the cool temperature.

The data for both temperature regimes of Expt. 1 may be explained by this type of mechanism. At 20/10C, the receptor is depleted or its activity is suppressed during the $10 \mathrm{C}$ portion of the thermoperiod. As a result, the $\mathrm{P}_{\mathrm{fr}}$-receptor complex cannot stimulate germination. When the chamber temperature increases to 20C, inhibition is gradually overcome, and, after 7 to $9 \mathrm{hr}$, a 1-hr light exposure results in maximum stimulation (Fig. 2). At 30/20C, a similar situation exists except that the temperature during the cool portion of the cycle is high enough to prevent complete formation of the "inhibiting" factor(s). Thus, the degree of stimulation that results as the inhibition dissipates is less than that observed at the 20/10C thermoperiod (Fig. 2).

At 20/10C, the 9-hr light exposure from 8:00 AM to 5:00 PM results in reduced germination compared to the 1-hr irradiations between 2:00 and 5:00 PM. Photoinhibition of this type, where short light exposures promote germination and long exposures inhibit, have been observed in seeds of several light-requiring species (Franklin and Taylorson, 1983; Negbi and Keller, 1964). It is not known why this photoinhibition does not manifest itself at the warmer 30/20C thermoperiod.

Since the absorption of light is temperature-independent, a 1$\mathrm{hr}$ exposure during any portion of a thermoperiod should result in formation of identical amounts of $\mathrm{P}_{\mathrm{fr}}$. If this $\mathrm{P}_{\mathrm{fr}}$ persisted throughout the entire 9-hr warm cycle, it could complex with its receptor as the low temperature suppression gradually diminished. Therefore, a 1-hr exposure in the morning or afternoon should result in equivalent germination. This does not occur, which indicates that, in Fraser fir, the $\mathrm{P}_{\mathrm{fr}}$ either undergoes proteolytic degradation (Pratt et al., 1974; Coleman and Pratt, 1974) or quickly reverts back to $P$, (for review, see Smith and Kendrick, 1976) following termination of the light stimulus. Similar "losses" of $\mathrm{P}_{\mathrm{fr}}$ in the dark have been documented with many in vivo systems (Butler et al., 1963; Butler and Lane, 1965; Kendricks and Franklin, 1968; Pratt and Briggs, 1966).

Data herein have implications for seed research and testing at alternating thermoperiods. Seeds of many species have either an obligate light requirement for germination and/or benefit from a daily irradiation. To assure reproducible results, one should first determine if the seeds in question are subject to control mechanisms similar to the ones discussed. If so, it should be determined at which time of day the light treatments result in 
optimal germination. This time should then be used routinely and mentioned when reporting methodology.

\section{Literature Cited}

Adkins, C.R. 1983. Effects of selected fungicides, surface sterilants and environmental factors on germination of Fraser fir seed. MS Thesis, N.C. State Univ., Raleigh.

Adkins, C. R., L. E. Hinesley, and F.A. Blazich. 1984. Role of stratification, temperature, and light in Fraser fir germination. Can. J. For. Res. 14:88-93.

Blazich, F.A. and L.E. Hinesley. 1980. Effects of temperature and light on Fraser fir seed germination. Proc. Southern Nurserymen's Assn. Res. Con f., 25th Annu. Rpt. p. 225-227.

Butler, W.L. and H.C. Lane. 1965. Dark transformations of phytochrome in vivo: H. Plant Physiol. 40:13-17.

Butler, W. L., H.C. Lane, and H.W. Siegelman. 1963. Nonphotochemical transformations of phytochrome in vivo. Plant Physiol. 38:514-519.

Coleman, R.A. and L.H. Pratt. 1974. Phytochrome: Immunocytochemical assay of synthesis and destruction. Planta 119:221-231.

Datta, N. and S.J. Roux. 1985, A rapid procedure for the purification of 124 kilodalton phytochrome from Avena. Photochem. and Photobiol. 41:229-232.

Downs, R.J. and J.F. Thomas. 1983. Phytotron procedural manual for controlled environment research at the southeastern plant environment laboratory. N.C. Agr. Res. Serv. Tech. Bul. 244. (revised.)

Franklin, B, and R. Taylorson. 1983. Light control of seed germination, p. 428-456. In: W. Shropshire, Jr., and H. Mohr (eds.). En- cyclopedia of plant physiology. vol. 16A. Photomorphogenesis. Springer-Verlag, New York.

Heit, C.E. 1968. Thirty-five years of testing tree and shrub seed. J. For. 66:623-634.

International Seed Testing Association. 1976. International rules for seed testing. Seed Sci. Technol. 4:3-117.

Kendricks, R.E. and B. Franklin. 1968. Kinetics of phytochrome decay in Amaranths seedlings. Planta 82:317-320.

Negbi, M. and D. Keller. 1964. Dual action of white light in the photocontrol of germination of Oryzopsis miliacea. Plant Physiol. 39:247-253.

Pratt, L.H. and W.R. Briggs. 1966. Photochemical and nonphotochemical reactions of phytochrome in vivo. Plant Physiol. 41:467474.

Pratt, L. H., G.H. Kidd, and R.A. Coleman. 1974. An immunochemical characterization of the phytochrome destruction reaction. Biochim. Biophys. Acts 365:93-107.

Smith, H. 1975. Phytochrome and photomorphogenesis. McGraw Hill, London.

Smith, H. and R.E. Kendrick. 1976. The structure and properties of phytochrome, p. 378424. In: T.W. Goodman (cd.). Chemistry and biochemistry of plant pigments. vol. 1. Academic, New York.

Song. P. 1983. The molecular basis of phytochrome (Pfr) and its interactions with model receptors, p. 181 -206. In: D.J. 'Cosens and D. Vince-Prue (eds.). The biology of photoreception. Cambridge Univ. Press, Cambridge, U.K.

Vierstra, R.D. and P.H. Quail. 1983. Purification and initial characterization of 124 kilodalton phytochrome from Avena. Biochemistry 22:2498-2505. 